\title{
GAMMA GLOBULIN COMPLEXES IN RHEUMATOID ARTHRITIS AND CERTAIN OTHER CONDITIONS
}

\author{
By H. G. KUNKEL, H. J. MÜLLER-EBERHARD, H. H. FUDENBERG AND \\ T. B. TOMASI
}

(From The Rockefeller Institute, Nero York, N. Y.)

(Submitted for publication July 15, 1960 ; accepted August 18, 1960)

Recent studies have demonstrated that the factors responsible for the various serological reactions currently employed for the diagnosis of rheumatoid arthritis represent macroglobulins which, in the isolated state, have a corrected sedimentation coefficient of approximately 19S (1-5). In serum and plasma, these proteins exist as complexes with low molecular weight $\gamma$-globulins and show a higher sedimentation rate, approximately $22 \mathrm{~S}$ $(6,7)$. It has become clear that the rheumatoid factors have a specific affinity for ordinary $\gamma$-glolulin showing a behavior, particularly in certain of the serological tests, like that of anti- $\gamma$-globulin antibodies. The possibility has been raised that the rheumatoid factor complex in serum represents an antigen-antibody complex.

During the course of investigation of the rheumatoid factors and their complexes through ultracentrifugal analyses of sera showing high titer reactions in the latex fixation test and $\gamma$-globulin precipitin test, another group of $\gamma$-globulin complexes was encountered. These had sedimentation rates between 9 and $17 \mathrm{~S}$ and were dissociated in urea and acid buffers in a manner similar to the previously observed dissociation of the rheumatoid factor complexes. Again the question arises as to whether these are antigen-antibody complexes or simple aggregates of $\gamma$-globulin.

Gamma globulin components in the 9 to $12 \mathrm{~S}$ range have been observed in many preparations of normal Fr II $\gamma$-globulin. The presumption has been that these represent aggregates formed in the process of chemical fractionation; they were not found in $\gamma$-globulin isolated by electrophoretic convection (8). Certain myeloma proteins have been found in which either the major component or accessory components have sedimentation rates in this range $(9,10)$. This has been particularly true of some of the more rapidly migrating myeloma proteins (11). Very little work has been carried out on these components particularly from the standpoint of association and dissociation, although Pedersen (12) described a myeloma protein with an s-rate of approximately $11 \mathrm{~S}$ at high protein concentrations and approximately $7 \mathrm{~S}$ at lower concentrations. Similar abnormal proteins have been encountered in certain ill-defined disorders (13). Particularly pertinent is a recent report of a macroglobulin studied by Rees and Resner (14) that could be dissociated in acid. Certain sera with similar proteins probably have been considered to represent macroglobulins of the Waldenström type and have been reported as such in the literature $(15,16)$, although the sedimentation rate of the main abnormal protein was lower than the 18 to $20 \mathrm{~S}$ range of the proteins described by Waldenström. Macroglobulins of the latter class are a homogeneous group and are known to be stable proteins which do not dissociate in urea and acid and alkaline buffers (17). They have specific immunological properties and dissociate in the presence of agents breaking disulfide bonds (18).

In the present study, sera from 11 different patients, 7 with classical rheumatoid arthritis, were found to contain multiple $\gamma$-globulin complexes. These were readily detected in whole serum and plasma by direct ultracentrifugal analysis. They did not possess rheumatoid factor activity but were associated in the same sera with large amounts of rheumatoid factor. Investigation of the association and dissociation reactions of these complexes was carried out and certain of their properties defined. Evidence for and against the hypothesis that they represent antigen-antibody complexes of the $\gamma$-globulin-anti- $\gamma$-globulin type was sought.

MATERIAL AND METIIODS

Six of the 11 patients whose sera were specifically analyzed in this study were observed in the clinic and outpatient department of the Rockefeller Hospital. Three of the remainder represented patients in various New York 

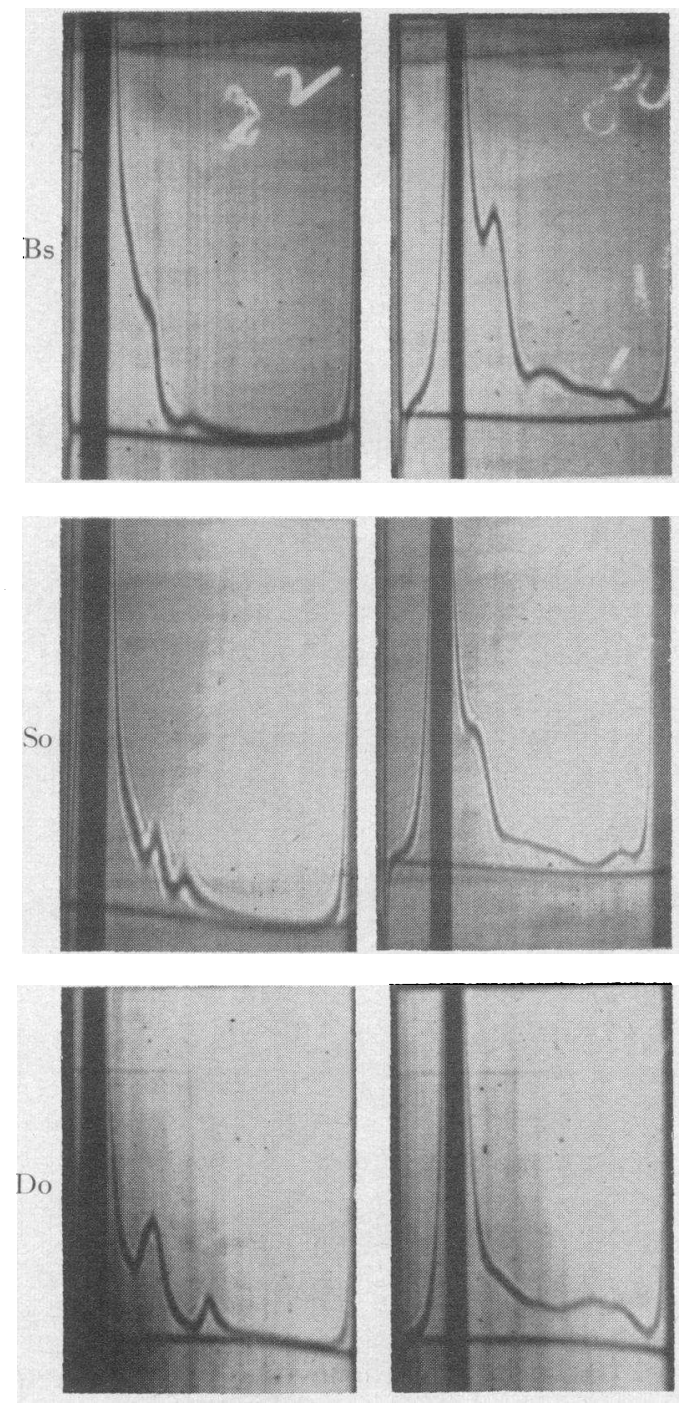

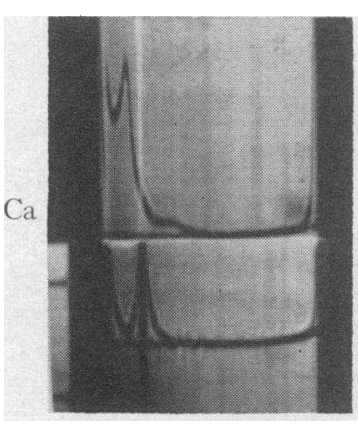

A

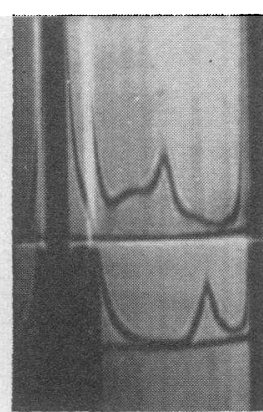

B
Fig. 1. Ultracentrifugal patterns from four sera SHOWING THE INTERMEdiate tYpe complexes. Photograph $A$ was taken at 32 minutes and $B$ at 80 minutes, with all sera diluted with an equal volume of isotonic saline. The bottom patterns are from a control serum showing primarily the normal $19 \mathrm{~S}$ peak.
TABLE I

Clinical diagnosis and age of the 11 patients included in the study

\begin{tabular}{clc}
\hline Patient & \multicolumn{1}{c}{ Diagnosis } & Age \\
\hline Do & Rheumatoid arthritis & 28 \\
So & Rheumatoid arthritis & 19 \\
$\mathrm{Cr}$ & Rheumatoid arthritis & 38 \\
$\mathrm{Ro}$ & Rheumatoid arthritis & 44 \\
$\mathrm{An}$ & Rheumatoid arthritis & 41 \\
$\mathrm{Wa}$ & Rheumatoid arthritis & 46 \\
$\mathrm{St}$ & Rheumatoid arthritis & 58 \\
$\mathrm{Bs}$ & Hepatosplenomegaly, \\
& slight arthritis & 66 \\
$\mathrm{Fi}$ & Idiopathic hepatomegaly \\
$\mathrm{Co}$ & and purpura & $\mathbf{5 5}$ \\
$\mathrm{Ca}$ & Idiopathic purpura & 24 \\
& Fever, purpura, lymphadenopathy ; & 14 \\
& unknown etiology & \\
\hline
\end{tabular}

hospitals whose sera were sent for ultracentrifugal analysis either for rheumatoid factor complex or for the usual macroglobulinemia. All of these patients were secondarily seen by one of the authors who attempted to evaluate the diagnosis of the local physician. One serum (Ro) came from a patient with rheumatoid arthritis under the care of Dr. Evan Calkins in Boston. Another, (Co) came from Dr. Corral in Havana, Cuba; this patient was not seen by the authors but he did not have arthritis. The clinical diagnosis was idiopathic purpura. The criteria for including the 11 cases in this study were that their sera contained more than 10 per cent of the total protein in the form of aggregates in the 9 to $17 \mathrm{~S}$ range (called intermediate complexes) and that these aggregates dissociated in acid buffers. Table I shows the age and clinical diagnosis of the 11 patients.

The ultracentrifugal and electrophoretic techniques were similar to those described previously (19). All specifically designated s-rates were obtained by infinite dilution extrapolation from sedimentation constants obtained at 2 or more protein concentrations. In some experiments a highly purified 19S Waldenström macroglobulin was added to serum or serum fractions to verify the position of the 19S peak where this was obscure. The position of the 19S components in Figure 1 was obtained in this way. The use of standard preparations of known s-rate for delineating proteins in complex mixtures was illustrated in a previous study (5). Euglobulin preparations were routinely made by diluting serum with $10 \mathrm{vol}$ of de-ionized distilled water. In certain instances, mentioned below, dialysis against phosphate buffer, $\mathrm{pH}$ 6.0, $\mathrm{r} / 20.02$, was utilized to prepare euglobulin components. Spontaneous precipitates were determined by the saline dilution method of Christian (7). Chromatographic experiments were carried out by the procedure of Sober, Gutter, Wyckoff and Peterson (20), utilizing a continuous $\mathrm{pH}$ and ionic strength gradient. 
The serological tests were carried out primarily as described previously (6). The latex fixation was determined after overnight standing in the cold room. A $1 / 20$ basic agglutination titer was used in the sensitized sheep cell test. The human $\mathrm{Rh}$ sensitized cell test was a modification of the technique of Waller and Vaughan (21) utilizing a single $\mathrm{Rh}$ antiserum for all determinations. This was selected from a group of $30 \mathrm{Rh}$ antisera for its reactivity with different rheumatoid factors. Inhibition reactions were studied by a modification of the procedure of Grubb and Laurell (22). The method was standardized with known inhibitor and non-inhibitor sera kindly provided by Drs. Laurell and Grubb.

\section{RESULTS}

Whole serum analyses. The sera of 11 different patients were found to contain a wide assortment of abnormal components visible by direct ultracentrifugal analysis of whole serum. Figure 1 illustrates the patterns from four of these cases along with a control serum showing slight elevation of the normal 19S component. In normal and control sera very little material is visible between the $19 \mathrm{~S}$ and $7 \mathrm{~S}$ components, and the pattern comes close to the baseline in this area. However, in each of the pathological sera illustrated, a continuous spectrum of components extends through this area. This is most apparent in the $\mathrm{B}$ frames which were taken at a later time. In addition, the first three sera llustrated-Bs, So and Doshowed a more rapidly sedimenting component which is visible only in the A frames and has completely sedimented in the $\mathrm{B}$ frames. It has a corrected s-rate between 22 and $28 \mathrm{~S}$ in these sera and represents in serum So and Bs the "22S" component previously described as characteristic of certain rheumatoid arthritis sera (6). In serum Do it had a considerably higher s-rate, approximately $28 \mathrm{~S}$. Serum Ca does not show such a component as a well defined peak, although some rapidly sedimenting material is visible.

Efforts to calculate the exact s-rates of the intermediate class substances were unsatisfactory because of the extreme heterogeneity of the components and because some differences were encountered at different dilutions of serum. Most of the sera showed some accentuation of the general elevation in the 10 to $12 \mathrm{~S}$ range and also in the 14 to $16 \mathrm{~S}$ range, but this was not always apparent, particularly in very late frames where the marked diversity of components was most apparent. Serum Ca showed somewhat more of 14 to $16 \mathrm{~S}$ material, as shown in the $\mathrm{B}$ frames of Figure 1 , sedimenting rather more slowly than the control 19S. Here again, however, later frames showed a complete spectrum of components from 7 to $19 \mathrm{~S}$. The concentration of the intermediate components showed considerable variation in the different sera. As mentioned above, the minimal concentration set for inclusion was 10 per cent of the total protein. The highest concentration was found in serum $\mathrm{St},{ }^{1}$ where approximately 43 per cent of the total protein was in the form of intermediate complexes. Sera Ca, Fi and Do had 31, 35 and 39 per cent, respectively. The remainder ranged from 10 to 30 per cent.

Euglobulin and $\gamma$-globulin fractions. A characteristic property of the 11 sera showing the intermediate components by ultracentrifugal analysis was a positive Sia test and a considerable precipitate on simple dilution with distilled water. In several instances this finding led to the initial ultracentrifugal analyses because of the possibility of macroglobulinemia of the Waldenström type. Analyses of these precipitates following solution in 5 per cent $\mathrm{NaCl}$ showed the characteristic intermediate components noted in whole serum. The lower portion of Figure 2 illustrates the pattern of the euglobulin fraction of serum Do at early and later times. The major peak is a rapidly sedimenting component with $\mathrm{s}_{20, \mathrm{w}}^{\circ}=22.8 \mathrm{~S}$, but

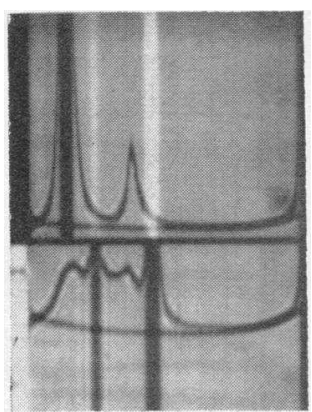

A

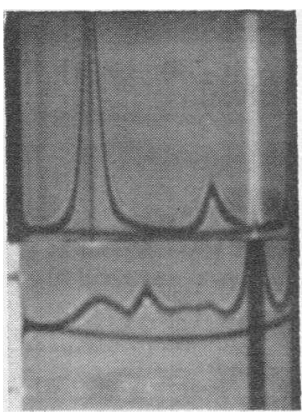

B
Fig. 2. Ultracentriflgal patterns of euglobulin FRACTIONS FROM SERCM DO AT EARLY AND LATER TIMES CTILIZING DOUBLE CENTRIFUGE CELls. Lower patterns show the euglobulin in 5 per cent $\mathrm{NaCl}$ solution. The upper patterns are the same euglobulin concentration in glycine- $\mathrm{HCl}$ buffer at $\mathrm{pH} 3.5$. There is complete disappearance of the intermediate complexes in the acid buffer.

1 Dr. Lospalluto and Dr. Ziff have also observed intermediate type complexes in this serum as well as in certain other rheumatoid arthritis sera (23). 


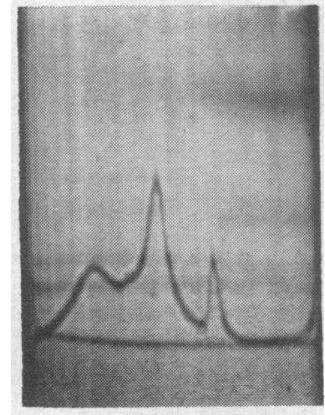

A

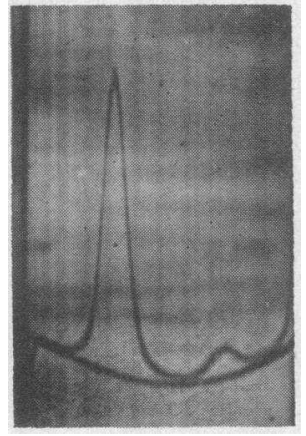

B
Fig. 3. Patterns of purified euglobulin fraction From SERUM Do (A) in 5 PER CENT NACl, ANd (B) IN $6 \mathrm{M}$ UREa. Complete dissociation of the intermediate complexes occurred in the urea.

the 9 to $17 \mathrm{~S}$ intermediate components are also very prominent. Figure $3 \mathrm{~A}$ illustrates another euglobulin pattern from this same serum. In this case the intermediate components were concentrated by differential euglobulin precipitation at $\mathrm{pH}$ 8.3. The higher s-rate components (19 to $28 \mathrm{~S}$ ) tended to precipitate more rapidly at lower $\mathrm{pH}$. It became evident that both the heavy component and the intermediate components were the fractions causing the high euglobulin levels. Serum $\mathrm{Ca}$ differed from the others in that the euglobulin precipitate did not dissolve in 5 per cent $\mathrm{NaCl}$ or dissolved only slightly. In this case the abnormal components which are present in whole serum appeared to be very readily altered so that they could not be redissolved in various buffers even in the presence of added albumin. However, in glycine- $\mathrm{HCl}$ buffer at $\mathrm{pH} 3.5$ or in $6 \mathrm{M}$ urea, soluble prepartions were readily obtained. These then consisted of almost pure $7 \mathrm{~S}$ material with a small 19S peak.

Zone electrophoretic experiments in various supporting media indicated that both the rapidly sedimenting component and the intermediate peaks were $\gamma$-globulins. Such analyses were carried out on sera Do, Ca and Bs, A considerable portion of the elevated $\gamma$-globulin noted in these sera was accounted for by the abnormal components. In serum Do the intermediate complexes made up 70 per cent of the $\gamma$-globulin. Some problems of recovery of these components were encountered following electrophoresis in these experiments, but they were not found in electrophoretic fractions other than the $\gamma$-globulin.
Dissociation. The intermediate peaks described above were readily and completely dissociable in the presence of $6 \mathrm{M}$ urea or glycine- $\mathrm{HCl}$ buffer, $\mathrm{pH} 3$ to 3.5 , giving rise to ultracentrifugally homogeneous components of the $7 \mathrm{~S}$ class. The $22 \mathrm{~S}$ peaks and those with higher s-rates were dissociated to a mixture of $7 \mathrm{~S}$ and $19 \mathrm{~S}$ fractions. Typical results of this type are shown in Figures 2 and 3. The euglobulin fractions which prior to dissociation consisted of many components, showed only two peaks, 7 and 19S, after acid or urea treatment. These conditions are known not to dissociate the 19S macroglobulins. Acetate and phosphate buffers in a $\mathrm{pH}$ range as high as 5.5 produced partial dissociation as did $4 \mathrm{M}$ urea. Table II shows the results of a typical experiment with a euglobulin preparation from serum Bs. The intermediate components with s-rates of 10.5 , 12.6 and 15.9 disappeared completely with a tremendous increase in the area of the $6.5 \mathrm{~S}$ peak following dissociation in acid. Similar dissociation results were also obtained with whole serum with marked reduction of the intermediate components (Figure 4). The results here were clear-cut when large amounts of complexes were present as in the two sera illustrated. However, when small amounts of complexes existed, difficulties were encountered due to interference by certain serum proteins and production of minor components resembling the complexes in normal serum with certain of the acid buffers. Gamma globulin preparations from sera Do, Bs and Fi showed complete dissociation in the acid buffers. Mercaptoethanol, which is known to dissociate the Waldenström type macroglobulin (18) had little or no effect on the intermediate peaks from euglobulin or $\gamma$-globulin preparations.

TABLE II

Corrected sedimentation rates and areas of euglobulin components from serum Bs before and after dissociation in acetate buffer

\begin{tabular}{|c|c|c|c|}
\hline \multicolumn{2}{|c|}{$\mathrm{NaCl}, 0.2 \%$} & \multicolumn{2}{|c|}{$\begin{array}{l}\text { Acetate buffer } \mathrm{pH} \\
4.2, \Gamma / 20.1\end{array}$} \\
\hline$s^{\circ} 20, w$ & $\%$ of total & $s^{\circ} 20, w$ & $\%$ of total \\
\hline 6.6 & 22 & 6.5 & 82 \\
\hline 10.5 & 26 & & \\
\hline 12.6 & 11 & & \\
\hline 15.9 & 14 & & \\
\hline 18.8 & 10 & 18.5 & 18 \\
\hline 21.6 & 17 & & \\
\hline
\end{tabular}




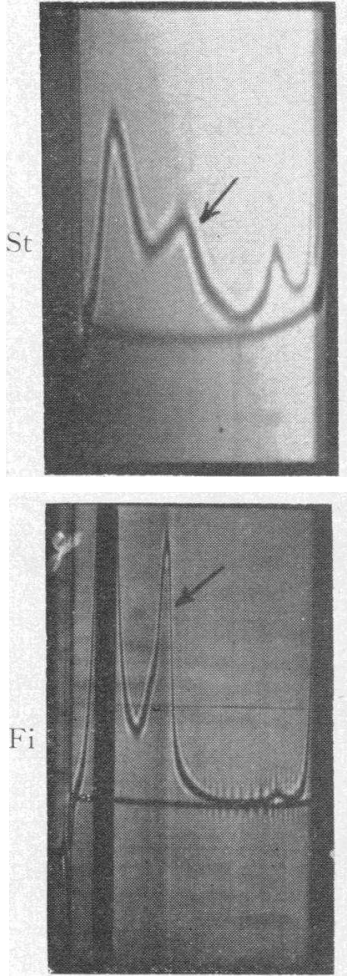

A
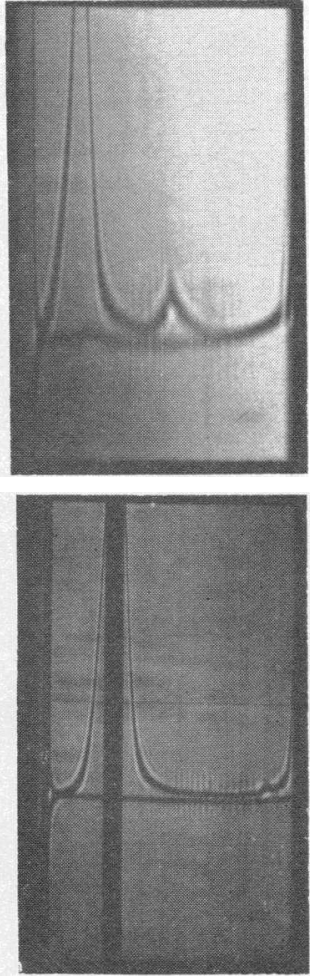

B
Fig. 4. Patterns of the whole serum of patients St and Fi diluted in isotonic saline (A) and acetate BUFFER, $\mathrm{PH} 4.5$ (B). The arrows indicate the large intermediate complexes which disappear in the acetate buffer.

Following dissociation, removal of the urea or acid by dialysis resulted in reformation of many intermediate complexes, although the exact pattern observed in the original englobulin fraction or serum was not quite reproduced. Figure 5 illustrates the distribution of components following dissociation in urea and again after dialysis against barbital buffer, $\mathrm{pH}$ 7.8. The original euglobulin fraction used was from serum Do and resembles that shown in Figure 2B, although this preparation contained considerably less of the large $22 \mathrm{~S}$ component shown in Figure 2B. The intermediate complexes were reformed in this experiment, but those with the s-rates above 19 were not.

In view of the complete dissociation of the intermediate complexes to $7 \mathrm{~S}$ units, the possibility arose that the components might be antigen-antibody complexes of the type $\gamma$-globulin-anti- $\gamma$ globulin. It seemed of interest to see the effect of adding additional $\gamma$-globulin. Several of the sera showing the largest amount of intermediate components contained very little free $\gamma$-globulin in the serum. This was particularly true of serum Do in which only a small $7 \mathrm{~S}$ component was visible in the ultracentrifugal pattern of whole serum and the $\gamma$-globulin fraction isolated by zone electrophoresis. The addition of Fr II $\gamma$-globulin (freed of aggregates by preparative ultracentrifugation) showed a striking effect. The whole range of complexes was markedly affected. The larger components disappeared almost entirely and resulted in the accumulation of a single large peak with an s-rate of approximately 10S. Each of the three sera shown in Figure 1 demonstrated a similar result both for the whole serum and for the euglobulin fraction. Figure 6 illustrates this effect for serum Ca. An amount of albumin equal to the $\gamma$-globulin was added as a control and no change was noted. The complexes in the presence of $\gamma$-globulin showed a marked shift to smaller complexes. Preparations of euglobulin Do, similar to that shown in Figure 2, illustrated this effect of added $\gamma$-globulin very dramatically.

As was mentioned above, certain of these sera contained complexes with an s-rate which was higher than the previously determined 22S for the usual rheumatoid factor complex. These ranged from 28 to $31 \mathrm{~S}$. This was particularly true of serum Do which showed extremely high titers in the rheumatoid factor tests. No $22 \mathrm{~S}$ component, as is usually seen in such patients, was observed, and the accumulated evidence indicated that the rheumatoid factor in this serum was in the $28 \mathrm{~S}$ component (Figure 1). This component disap-

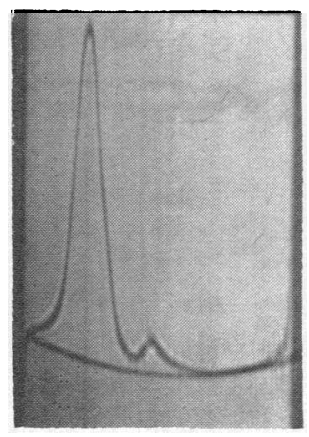

A

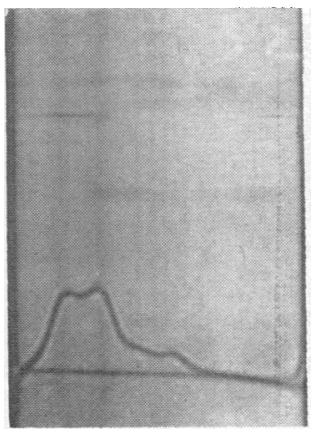

B
Fig. 5. Reformation of intermediate complexes From a dissociated ecglobllin fraction. A, euglobulin in urea; $B$, euglobulin in urea followed by dialysis against barbital buffer. 
peared after precipitation with aggregated $\gamma$-globulin. Euglobulin fractions on the other hand showed a large $22 \mathrm{~S}$ component. This is visible in the lower portion of Figure 2, sedimenting slightly faster than the $19 \mathrm{~S}$ component visible in the upper frames after dissociation in acid buffer. At least five examinations of whole serum Do at different dilutions always showed the rapidly sedimenting peak with an s-rate higher than the usual 21 to $23 \mathrm{~S}$ for the rheumatoid factor. However, on the addition of $7 \mathrm{~S} \gamma$-globulin to the whole serum, as described in the preceding paragraph, this rapidly sedimenting peak showed a shift in s-rate to close to $22 \mathrm{~S}$ with a definite loss of area. It appeared that in the presence of low $7 \mathrm{~S} \gamma$-globulin levels in this serum, the rheumatoid factor complexed with intermediate type aggregates of $\gamma$-globulin giving the higher s-rates. When excess $7 \mathrm{~S}$ $\gamma$-globulin was added, these aggregates were replaced by the usual $7 \mathrm{~S}$ moieties and the rheumatoid factor complex assumed its usual s-rate. Just why the euglobulin fraction did not show the $28 \mathrm{~S}$ component was not entirely clear; relatively more $7 \mathrm{~S} \gamma$-globulin appeared to be present than in whole serum, which may have arisen from dissociation of some of the complexes, and this may have caused a shift to the lower s-rate. The $28 \mathrm{~S}$ complex was present, however, in the $\gamma$-globulin isolated by zone electrophoresis.

Serum St, which had the greatest amount of intermediate complexes, also showed a large, rapidly sedimenting peak. In this case the s-rate was calculated as $\mathrm{s}^{\circ}{ }_{20, \mathrm{w}}=31 \mathrm{~S}$. This peak also showed a marked shift in the presence of excess

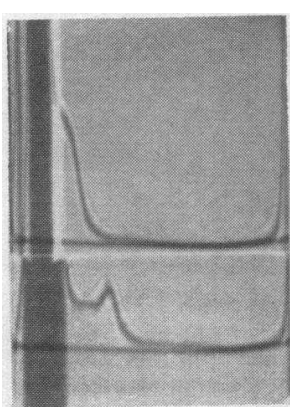

A

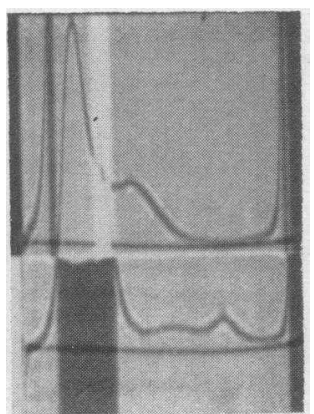

B
Fig. 6. The EFFect of addition of Isolated 7S $\gamma$-GLOBULIN ON THE DISTRIBUTION OF THE INTERMEDIATE COMPLEXES. Lower patterns with albumin added show no effects; upper patterns, with $\gamma$-globulin added, show a shift to smaller complexes.

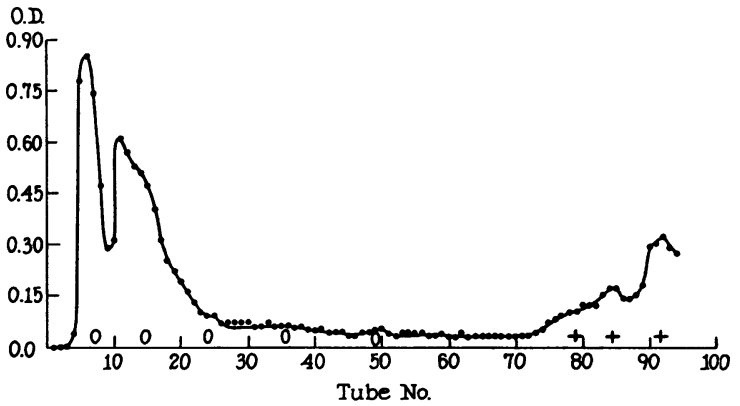

Fig. 7. Distribution of COMponents obtained By DEAE COLUMN CHROMATOGRAPHY OF THE EUGLOBULIN FRACTION OF SERUM Do. The signs under the peaks designate rheumatoid factor activity in the sensitized $\mathrm{Rh}_{0}$ test. The intermediate complexes were found in the peak of tubes 11 to 20 and were devoid of activity. The $19 \mathrm{~S}$ class fractions appeared beyond tube 70 and showed the activity.

$7 \mathrm{~S} \gamma$-globulin with conversion to the usual $22 \mathrm{~S}$ class.

Complex formation with addition of $\gamma$-globulin. One serum ( Fi) demonstrated a marked increase in intermediate complexes when $\gamma$-globulin was added, an effect that was not observed with the other sera where simply a shift to smaller complexes occurred. Here there was evidence that free material was present in the serum which was capable of reacting with added $\gamma$-globulin. The addition of $7 \mathrm{~S} \gamma$-globulin to this serum actually produced a fall in the $7 \mathrm{~S}$ peak of the serum with a marked increase in material sedimenting at approximately $10 \mathrm{~S}$.

Studies with purified complexes. Purified preparations of intermediate complexes, such as those illustrated in Figure 3A which had been prepared by differential euglobulin precipitation, still contained substantial amounts of $7 \mathrm{~S}$ and 19S $\gamma$-globulin. Further purification was achieved by zone ultracentrifugation in a sucrose density gradient. Approximately 25 fractions were taken from the bottom of the tube by means of a fraction collector. Protein analyses on these fractions showed three major peaks corresponding to those shown in Figure 3A. The middle peak, when examined in the analytical ultracentrifuge, showed 70 per cent 9 to $14 \mathrm{~S}$ material and 30 per cent $7 \mathrm{~S}$. Further efforts at greater purification of this fraction, by both differential precipitation and density gradient centrifugation, resulted in increasing quantities of $7 \mathrm{~S} \gamma$-globulin and small complexes in the 9 to $10 \mathrm{~S}$ range. It became apparent that the complexes 
continually dissociated with purification and that they were extremely difficult if not impossible to isolate completely. This behavior was very similar to that previously noted for the $22 \mathrm{~S}$ rheumatoid factor complex; with purification, dissociation occurred and 19S rheumatoid factor resulted.

Considerable purification was also achieved on diethylaminoethyl (DEAE) cellulose columns and the complexes caused the appearance of a large peak not ordinarily observed in the separation of serum. The pattern obtained for the euglobulin from Do is illustrated in Figure 7. The complexes were found in the peak of tubes 11 to 20 . However, as in the case of the purified fractions isolated above, considerable $7 \mathrm{~S}$ material was observed by ultracentrifugal analysis of pooled material from these fractions.

Both in the crude and in the purified state the complexes dissociated in acid buffers to units which were indistinguishable from ordinary $7 \mathrm{~S}$ $\gamma$-globulin. Mixing experiments with added 7S gave single peaks. Immunological analyses were also attempted with the middle fraction isolated from the density gradient tube as described above. Both by Ouchterlony plate analysis and immunoelectrophoresis, no antigen other than ordinary $7 \mathrm{~S} \gamma$-globulin was detected. In these studies a number of antisera was employed, made against whole serum, Fr II and whole electrophoretic $\gamma$-globulin. Antisera were not made against the complexes. Efforts to detect materials with $\beta_{2 A}$ or $\beta_{2 \mathrm{M}}$ specificity in the complexes were unsuccessful.

One purified preparation was obtained from serum $\mathrm{Fi}$ by zone electrophoresis of a euglobulin fraction. This consisted of 81 per cent $10 \mathrm{~S}$ material and the remainder mainly of $7 \mathrm{~S}$. This preparation contained no visible $19 \mathrm{~S}$ peak. Carbohydrate assays were performed following a second electrophoresis in polyvinyl chloride medium as described previously (24). Each fraction contained approximately 1.5 per cent hexose sugars. There was no evidence of a carbohydrate-rich material in the complexes, and the values were very similar to those obtained for ordinary $7 \mathrm{~S} \gamma$-globulin (24).

Incidence and distribution of complexes. It is difficult from this study to determine the exact incidence of the intermediate type complexes either in rheumatoid arthritis or in other disease condi- tions. The 11 cases described above were selected because of extremely large amounts of the intermediate complexes at a time when wide varieties of sera were examined in the ultracentrifuge. These were from patients with elevated $\gamma$-globulin levels and particularly from those showing high euglobulin fractions and positive Sia tests. $\mathrm{Pa}$ tients with liver disease, macroglobulinemia, myeloma, leukemia, parasitic disease, sarcoid, and others, were studied. Also, a large number of high titer rheumatoid arthritis sera was examined. Eight of the 11 cases came from the latter group. Seven were typical severe rheumatoid arthritis patients with two showing a positive lupus erythematosus test along with severe arthritis. The eighth case, Bs, although showing some rheumatoid arthritic changes, was atypical and represented somewhat of a diagnostic problem because of liver enlargement. All eight of these sera were characterized by extremely high titers in the various tests for rheumatoid factor. Of the remaining three sera, one (serum Ca) was from a 14 year old girl who had no evidence of arthritis and suffered from intermittent low-grade fever, purpura and general glandular enlargement of unknown etiology. Lymph node biopsy was read by one pathologist as lymphoblastoma, by another as nonspecific lymphadenitis. The illness was present without progression for four years. This serum

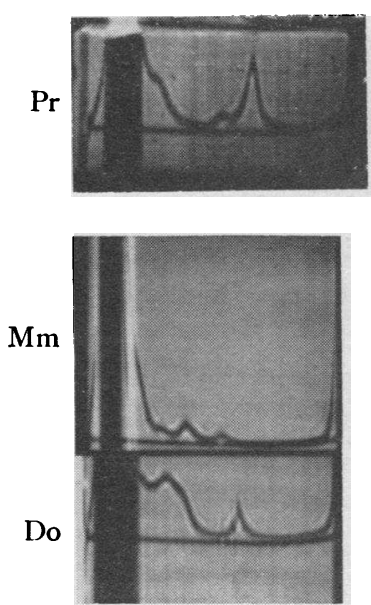

A
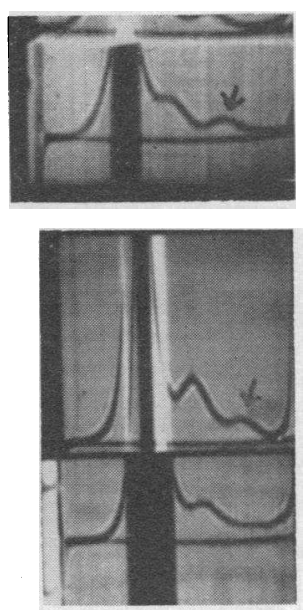

B
Fig. 8. Ultracentrifugal patterns of two addiTIONAL RHEUMATOID ARTHRITIS SERA, SHOWING SMALLER amounts of Intermediate complexes. Serum Do is illustrated again for comparison. The arrows in the later (B) frames show material of approximately $10 \mathrm{~S}$ in each case. 
TABLE III

Results of rheumatoid factor tests in the 11 patients showing intermediate complexes

\begin{tabular}{lrrr}
\hline \hline Patient & $\begin{array}{r}\text { Latex } \\
\text { fixation }\end{array}$ & $\begin{array}{c}\text { Sensitized } \\
\text { sheep cell }\end{array}$ & $\begin{array}{c}\text { Tanned } \\
\text { cell }\end{array}$ \\
\hline Do & 640,000 & 80,000 & \\
So & 160,000 & 20,000 & \\
Cr & 20,000 & & \\
Ro & 10,000 & 1,280 & \\
An & 5,000 & 5,000 & \\
Wa & & 2,560 & \\
St & 800,000 & 200,000 & 10,000 \\
Bs & 20,000 & 640 & \\
Fi & 20,000 & 16 & \\
Co & 2,560 & 128 & 10,000 \\
Ca & 10,000 & 2,560 & \\
\hline
\end{tabular}

differed somewhat from the others in a number of respects. First, the titers in the various serological tests were not as high as for most of the other cases. Second, a marked precipitate formed on simple dilution of the serum with saline even at room temperature. This interfered with the precipitin reaction with aggregated $\gamma$-globulin and perhaps with the other serological tests. Analysis of the precipitate produced with aggregated $\gamma$-globulin after solution in acid buffers showed primarily $7 \mathrm{~S} \gamma$-globulin and not the usual predominance of the $19 \mathrm{~S}$ fraction. Third, the insolubility of the euglobulin fraction in salt solutions, mentioned above, stood in marked contrast to the euglobulin of the other sera studied. The second nonrheumatoid serum was from a young woman with very severe purpura which was diagnosed as hyperglobulinemic purpura. She has been extensively studied by Dr. Corral of Havana, Cuba, and her case will be published in detail separately. The third patient of this group without arthritis ( $\mathrm{Fi}$ ) showed relatively few clinical symptoms. Enlargement of the liver and spleen led to hospitalization and the finding of the protein abnormalities. This patient also had one episode of generalized purpura.

A high incidence of intermediate type complexes in rheumatoid arthritis, relative to other conditions, appears likely from the distribution of the cases described above. In addition to the seven or possibly eight cases described, a considerably larger group of rheumatoid arthritis sera appeared to show intermediate complexes in smaller amounts. Figure 8 illustrates the patterns from two of these cases-both patients with severe rheumatoid arthritis and uniquely high titers in the serological reactions. For comparative purposes the pattern of serum Do is shown again. The early frames (A) show $22 \mathrm{~S}$ components for $\mathrm{Pr}$ and $\mathrm{Mm}$, giving an extremely high peak in $\mathrm{Pr}$ which sediments just ahead of the 19S peak. In $\mathrm{Mm}$ a third peak is visible, sedimenting slightly more slowly than the $19 \mathrm{~S}$ component, with a calculated $\mathrm{S}^{\circ}{ }_{20, w}$ of $16 \mathrm{~S}$. The later frames (B) show the delineated $7 \mathrm{~S}$ component in all three sera in the mid-portion of each frame. In $\mathrm{Pr}$ and $\mathrm{Mm}$ a clear peak is visible sedimenting ahead of the $7 \mathrm{~S}$ which has an s-rate of approximately $10 \mathrm{~S}$ in each case. These peaks resemble those in serum Do and the others described earlier when excess $7 \mathrm{~S}$ $\gamma$-globulin is added to the serum. They are definitely abnormal components and normal serum has little or no material sedimenting in this position. Most other high titer rheumatoid arthritis sera showed similar components and the predominant abnormal component was usually in the 9 to $11 \mathrm{~S}$ range. These sera have not been included in the present series because of less certainty regarding these components. They were more difficult to study because of their low concentration, and it was not always clear that they dissociated to $7 \mathrm{~S}$ units. However, it appears likely that they represent smaller amounts of complexes similar to those in the 11 sera described above.

Activity of complexes. Table III shows the titer of the eight sera in various serological tests for rheumatoid factor. Table IV demonstrates the titer of three of the sera in the Rh sensitized cell test. In addition, the inhibition titer of these sera in the Gm inhibitor system is indicated (22). The anti- $\mathrm{Rh}_{0}$ system used in this experiment gives

TABLE IV

Inhibition titers in the Grubb system of three of the sera from patients showing $\gamma$-globulin complexes

\begin{tabular}{lll}
\hline \multicolumn{1}{c}{ Patient } & $\begin{array}{c}\text { Agglutination } \\
\text { titer* }\end{array}$ & $\begin{array}{c}\text { Inhibition } \\
\text { titert }\end{array}$ \\
\hline Bs & $1 / 160$ & $1 / 3,096$ \\
Do & $1 / 1,600$ & $1 / 2,048$ \\
St & $1 / 40$ & $1 / 4,096$ \\
Ca & 0 & $1 / 2,048$ \\
Inh (H.F.) & 0 & $1 / 64$ \\
Non-Inh (H.H.) & 0 & $1 / 1$
\end{tabular}

* The $\mathrm{Rh}$ serum used for these titers was separate from that used for inhibition titers.

$\dagger$ All serum inhibition titers measured with standard rheumatoid serum no. $19 \mathrm{~N}$ ( $1 / 20$ dilution) for Gm-grouping. 
a good distinction between the hereditary $\gamma$-globulin groups of Grubb and Laurell (22) without showing strong agglutination with most rheumatoid sera. It is clear that the sera under study showed very great inhibitor activity compared with a normal serum belonging in the $\mathrm{Gm}\left(\mathrm{a}^{+}\right)$or inhibitor group. Such inhibitor titers were not encountered with other pathological sera with the exception of certain myeloma sera, and the evidence suggests that the complexes were responsible for the inhibition.

Considerable efforts were directed toward finding additional biological activity for the intermediate components. The accumulated evidence indicated that they did not show typical activity as rheumatoid factors in the various serological tests. Density gradient analysis of these sera by methods described previously (25), showed the major activity in the bottom fractions containing $19 \mathrm{~S}$ or greater classes of proteins. The intermediate fractions which were demonstrated to contain the complexes were devoid of activity. This was also the case with the complexes isolated by chromatography (Figure 7 ). There was no activity in the peak containing the complexes, and all the activity was in the later fractions containing the $19 \mathrm{~S}$ class proteins. Most of the isolated complexes also failed to react in the precipitin test with $\gamma$-globulin aggregates and soluble antigen-antibody complexes. However, the complexes from sera $\mathrm{Ca}$ and St, which were relatively insoluble, showed intensified precipitation in the presence of aggregated $\gamma$-globulin, although they failed to give positive reactions in the serological tests. Evidence was also obtained with several sera that the complexes intensified the precipitation reaction with aggregates and caused larger amounts of $7 \mathrm{~S}$ $\gamma$-globulin to appear in acid-clissolved precipitates (1). The question of whether this indicated actual participation in the reaction, or simply coprecipitation as a result of their general insolubility, was not entirely clear.

Some evidence was obtained that these complexes played a primary role in spontaneous precipitation from serum (7). Certainly, serum Ca gave an insoluble precipitate on standing, and on dilution with isotonic saline a large amount of precipitate formed. Here the rheumatoid factor did not appear to be directly involved, and the precipitate was almost entirely composed of the intermediate aggregates. Sera Bs and St also showed considerable spontaneous precipitate. However, Do which had both large amounts of intermediate complexes as well as extreme titers in the rheumatoid factor tests, showed almost no precipitate in whole serum standing in the cold room and only a small amount on 1/10 dilution with isotonic saline and standing in the cold room. The remaining sera were not specifically checked from this point of view.

\section{DISCUSSION}

The ready dissociation of the intermediate type components described above indicates clearly that they represent complexes. The dissociated unit showed a homogeneous peak in the ultracentrifuge with an s-rate of approximately $7 \mathrm{~S}$. Certainly, they were in part ordinary $7 \mathrm{~S} \gamma$-globulins as shown by the immunological reaction with antiserum to normal $\gamma$-globulin. No evidence for additional constituents was obtained and the accumulated evidence suggested that the complexes were composed entirely of $7 \mathrm{~S} \gamma$-globulin units. The fact that normal $7 \mathrm{~S} \gamma$-globulin, when added to these complexes, had a profound effect on their distribution was of special interest. The larger complexes disappeared and primarily one type with an s-rate of approximately $10 \mathrm{~S}$ remained. These results suggested that one constituent of the complexes was ordinary $\gamma$-globulin which could be influenced and replaced by $\gamma$-globulin from other sera. The major question which is raised is whether or not the remainder of the complex is antibody to $\gamma$-globulin. Certainly, the effect of extraneous $\gamma$-globulin suggests the action of excess antigen on antigen-antibody complexes causing the formation of limiting complexes. In the case of bivalent antibodies, these would be composed of three units of $\gamma$-globulin. However, the broadness of the peaks and the spread of the added $7 \mathrm{~S}$ $\gamma$-globulin made it difficult to decide between limiting complexes composed of two or three units of $\gamma$-globulin.

Recent evidence has indicated a marked affinity of the rheumatoid factors for the $\gamma$-globulin of specific individuals (26). The specificity of this reaction offers strong support for the concept that these proteins represent high molecular weight antibodies to $\gamma$-globulin. Attempts were made in 
the present study to demonstrate a similar specificity of the active portion of the intermediate complexes. Largely for technical reasons this was not accomplished, although further work in this direction is continuing. Some of the effects of added $\gamma$-globulin on the complexes could be better explained on the basis of greater reactivity with certain types of $\gamma$-globulin than simply on the basis of excess $\gamma$-globulin effects. If the active portion of the complexes is antibody to $\gamma$-globulin, as is certainly suggested, it must be of a nonprecipitating type in most of the sera studied.

The one serum which showed formation of additional complexes when $\gamma$-globulin was added was of special interest in this connection. Here insufficient $\gamma$-globulin appeared to be present to combine with the active fraction, and further $\gamma$-globulin was required to form the maximal number of complexes. The marked affinity of this patient's $\gamma$-globulin for extraneous $\gamma$-globulin was clearly evident.

The failure to find complexes of this type larger than $17 \mathrm{~S}$ in any of the sera suggested a definite limitation on the polymerization and along with their nonprecipitating character raises the possibility of a univalent type of antibody.

The association between the presence of intermediate complexes and rheumatoid factor in the 11 sera described was striking. However, it certainly was not an absolute or direct relationship. All the rheumatoid arthritis sera showing large amounts of the complexes had high titers in the rheumatoid factor tests. On the other hand, a number of other sera with extremely high titers by these serological reactions did not show such large amounts of complexes. Evidence was obtained that many of these did show smaller amounts of similar components but their complete identity with the others was difficult to establish. The association, at least in a number of sera, suggests that the active portion of these complexes represents the $7 \mathrm{~S}$ counterpart of the $19 \mathrm{~S}$ group of rheumatoid factors. It is well known in such instances as the typhoid agglutinins and isoagglutinins that $19 \mathrm{~S}$ antibodies are usually not the sole type but occur along with ordinary $7 \mathrm{~S}$ antibodies (25). If the $19 \mathrm{~S}$ rheumatoid factors are indeed antibodies one would expect to find similar 7S types. These would give rise to complexes with ordinary $\gamma$-globulin just as the rheumatoid factors give rise to the $22 \mathrm{~S}$ complex. Several of these sera showed the latter complex along with the intermediate type complexes. It is of special interest that several of the sera showed a large peak with an unusually high s-rate ( 28 to $31 \mathrm{~S}$ ). Evidence was obtained that this represented rheumatoid factor complexed with intermediate complexes. This component disappeared on the addition of excess ordinary low molecular weight $\gamma$-globulin and then became the more usual 22S fraction. It was apparent that a wide assortment of complexes occurred in these sera, so much so that in some instances little or no $\gamma$-globulin remained in the uncombined state. The fact that the complexes did not show typical rheumatoid factor activity is not conclusive evidence against their being the 7S counterparts of the $19 \mathrm{~S}$ rheumatoid factors. It is well known that high molecular weight antibodies are particularly good agglutinators and the $7 \mathrm{~S}$ antibodies often fail in this respect, as in the case of the $\mathrm{Rh}$ antibodies. Furthermore, the combination with other $7 \mathrm{~S}$ units might block the participation in the agglutination reactions more than in the case of the $19 \mathrm{~S}$ rheumatoid factors.

No clear results were obtained which suggested a direct harmful biological role for these complexes. It seems possible and indeed almost probable that under certain conditions they would precipitate. This would seem to be particularly likely in the presence of low $\gamma$-globulin levels which would tend to favor larger complexes. In most situations excess $\gamma$-globulin would keep the complexes small and adequately soluble. It seems somewhat surprising that the intermediate complexes did not precipitate with rheumatoid factor, but this is in line with previous evidence that precipitation occurred only when very large soluble complexes or aggregates were added (26). Perhaps some such precipitation does occur in vivo. The problem appears related to that of the spontaneous precipitates clescribed by others as occurring in certain rheumatoid arthritis sera. A final conclusion on this point was not obtained, because certain of the sera with large amounts of complexes did not show significant spontaneous precipitation even after dilution with saline. The complexes also appeared different from the components noted by Christian (7) in certain spontaneous precipitates dissolved in acid. Such conditions would 
dissociate the complexes described in this study to ordinary $7 \mathrm{~S}$ units. Another possible biological activity found for the intermediate type complexes was an inhibition effect in certain of the rheumatoid factor agglutination reactions. This was observed in the Grubb and Laurell Gm(a) system employing sensitized $R h_{0}$ positive human red cells.

Consideration certainly should be given to the possibility that the complexes represent simple aggregates of $\gamma$-globulin of the type observed in certain Fr II preparations. Most observers feel that these result from the isolation procedures, but the possibility remains that they represent in part complexes existing in small amounts in normal serum that are concentrated by the isolation procedures. Some $\gamma$-globulin preparations isolated from normal serum by zone electrophoresis and normal euglobulin fractions show similar components that appear to be present in the original serum. It seems probable that some of the latter are more closely related to the $\mathrm{C}_{3}^{\prime}$ complex recently described (27) which is also a euglobulin. Another possibility is that a $\gamma$-globulin is produced, in the group of patients described, which has a specific property of polymerizing with other $\gamma$-globulin molecules. The $\beta_{2 \mathrm{~A}}$-protein, which is related to ordinary $\gamma$-globulin immunologically, has been found to have unusual complexing tendencies, and Heremans has recently described a $\beta_{2 \mathrm{~A}}$-albumin complex (28). However, the low carbohydrate content of the complexes and the failure to find significant $\beta_{2 \mathrm{~A}}$ specificity immunologically, make this possibility unlikely.

It appears highly probable that cases similar to the present group have been noted in the past and classified as Waldenström's macroglobulinemia. The distinction is not readily made unless dissociation experiments are carried out. Both types show positive Sia tests. Serum Fi, illustrated in Figure 4, showed a pattern closely resembling that seen in Waldenström's macroglobulinemia with a huge, relatively sharp peak with an s-rate of approximately 15S. Close inspection of this pattern, however, reveals minor differences even without resorting to dissociation analysis. The main peak has a slight shoulder of lower s-rate. This has never been encountered in the true macroglobulinemias. Also the higher polymers, which are so characteristic of the latter syndrome (17), are missing. The interesting case reported by
Conrad, Ramos, Howie and Crosby (29), which was proven by Rees and Resner (14) to have acid-dissociable components in the serum, is called Waldenström's macroglobulinemia. This case was undoubtedly similar to those in the present series, although rheumatoid factor tests were not described. To prevent confusion and since the proteins involved are quite different, it seems better to avoid the term macroglobulinemia in referring to these cases.

Unfortunately, no sensitive method comparable with the serological tests for rheumatoid factors is available to measure the intermediate complexes or their active constituents. It seems probable that if such a procedure were devised a considerably higher incidence in rheumatoid arthritis would be found. Previous experience with the rheumatoid factors has demonstrated the insensitivity of the ultracentrifuge and only the extremely high titer sera showed the $22 \mathrm{~S}$ rheumatoid factor complex. It is impossible to answer conclusively the question of relationship to clinical manifestations of disease. Certainly, most of the cases showing large amounts of intermediate complexes suffered from severe and long-standing joint disease; but three of the cases showed no arthritis at all. Some of the patients showet idiopathic purpura that might be related to the protein changes but again others in the group failed to show this. Further observations with more sensitive techniques are required to clarify many of these points. However, irrespective of their outcome, it appears abundantly clear that these complexes represent another unusual protein alteration found in the sera of certain patients with rheumatoid arthritis.

\section{SUMMARY}

The sera of 11 patients, 7 with advanced rheumatoid arthritis, 1 with questionable rheumatoid arthritis, and 3 with obscure disorders, showed large amounts of unusual $\gamma$-globulin complexes with sedimentation rates ranging from 9 to $17 \mathrm{~S}$. These were observed by direct ultracentrifugal analyses of whole serum as well as $\gamma$-globulin and euglobulin fractions. In some sera they made up most of the $\gamma$-globulin fractions.

The complexes were readily dissociated to $7 \mathrm{~S}$ units in acid buffers and in 4 to $6 \mathrm{M}$ urea. Addi- 
tion of normal 7S $\gamma$-globulin to the sera and euglobulin fractions produced marked effects on the complexes. A pronounced shift to lower s-rate components was observed with disappearance of the larger 12 to $17 \mathrm{~S}$ moieties.

The complexes were devoid of rheumatoid factor activity but were present in sera showing high titers in the serological reactions for rheumatoid factor. This relationship, however, was not a direct one. The complexes demonstrated strong inhibiting activity in certain of these reactions and were found to complex with rheumatoid factors, giving rise to components with s-rates as high as 28 to $31 \mathrm{~S}$. Some evidence was obtained for a relationship to "spontaneous precipitates."

The difficulties involved in distinguishing certain of these sera from those of Waldenström's macroglobulinemia and the importance of acid dissociation experiments are discussed.

The possibility is raised that these complexes might represent antigen-antibody complexes of the $\gamma$-globulin-anti- $\gamma$-globulin type. Evidence is presented suggesting that they are the 7S counterparts of the 19S rheumatoid factors combined with ordinary $\gamma$-globulin. Further observations with a more sensitive method of detection are required to determine the exact incidence and distribution of these complexes in rheumatoid arthritis and other diseases.

\section{ACKNOWLEDGMENT}

The authors are very much indebted to Dr. Elliott Osserman for supplying serum St and to Dr. Fenton Schaffner for supplying serum $\mathrm{Fi}$, as well as for valuable discussion regarding these two cases.

\section{REFERENCES}

1. Franklin, E. C., Kunkel, H. G., Müller-Eberhard, H. J., and Holman, H. R. Relation of high molecular weight proteins to the serological reactions in rheumatoid arthritis. Ann. rheum. Dis. 1957, 16, 315.

2. Lospalluto, J., and Ziff, M. Chromatographic studies of the rheumatoid factor. J. exp. Med. 1959, 110, 169.

3. Heimer, R., Federico, O. M., and Freyberg, R. H. Purification of a rheumatoid factor. Proc. Soc. exp. Biol. (N.Y.) 1958, 99, 381.

4. Williams, R. R., Stewart, L. C., and Jenkins, J. C. Purification and isolation of rheumatoid factor. Proc. Soc. exp. Biol. (N.Y.) 1958, 99, 554.
5. Kunkel, H. G., Franklin, E. C., and Müller-Eberhard, H. J. Studies on the isolation and characterization of the "rheumatoid factor." J. clin. Invest. 1959, 38, 424.

6. Franklin, E. C., Holman, H. R., Müller-Eberhard, H. J., and Kunkel, H. G. An unusual protein component of high molecular weight in the serum of certain patients with rheumatoid arthritis. J. exp. Med. 1957, 105, 425.

7. Christian, C. L. A study of rheumatoid arthritis sera: Comparison of spontaneous precipitates and gamma globulin induced precipitates. Arth. Rheum. 1959, 11, 289.

8. Cann, J. R., Brown, R. A., Singer, S. J., Shumaker, J. B., Jr., and Kirkwood, J. G. Ultracentrifugal studies of $\gamma$-globulins prepared by electrophoresisconvection. Science 1951, 114, 30.

9. Petermann, M. L., Hamilton, M. G., and Korngold, L. Multiple-myeloma proteins. II. Ultracentrifugal and electrophoretic analysis of paucidisperse myeloma globulin. Cancer (Philad.) 1956, 9, 193.

10. Kekwich, R. A. The serum proteins in multiple myelomatosis. Biochem. J. 1940, 34, 1248.

11. Slater, R. J., Ward, S. M., and Kunkel, H. G. Immunological relationsips among the myeloma proteins. J. exp. Med. 1955, 101, 85.

12. Pedersen, K. O. Size relationship among similar proteins: Association and dissociation reactions of protein units. Cold Spr. Harb. Symp. quant. Biol. 1949, 14, 140.

13. Motulsky, A. G., Eriksen, N., Volwiler, W., and Donohue, D. Significance of macroglobulins. Trans. 6th Congr., European Society of Haematology, 1957, Part 2, 150.

14. Rees, E. D., and Resner, R. Dissociation of a human serum macroglobulin in acid buffer. Clin. chim. Acta 1959, 4, 272.

15. Zlotnick, A. Macroglobulinemia of Waldenström. Amer. J. Med. 1958, 24, 461.

16. Sehon, A. H., Gyenes, L., Gordon, J., Richter, M., and Rose, B. Physico-chemical and immunologic studies on macroglobulins. J. clin. Invest. 1957, $36,456$.

17. Müller-Eberhard, H. J., and Kunkel, H. G. Ultracentrifugal characteristics and carbohydrate content of macromolecular $\gamma$-globulins. Clin. chim. Acta 1959, 4, 252.

18. Deutsch, H. F., and Morton, J. I. Dissociation of human serum macroglobulins. Science 1957, 125, 600.

19. Wallenius, G., Trautman, R., Kunkel, H. G., and Franklin, E. C. Ultracentrifugal studies of the major non-lipide electrophoretic components of normal human serum. J. biol. Chem. 1957, 225, 253.

20. Sober, H. A., Gutter, F. J., Wyckoff, M. M., and Peterson, E. A. Chromatography of proteins. II. Fractionation of serum proteins on anion-exchange cellulose. J. Amer. chem. Soc. 1956, 78, 756. 
21. Waller, M. V., and Vaughan, J. H. The use of anti$\mathrm{Rh}$ sera for demonstrating agglutination activating factor in rheumatoid arthritis. Proc. Soc. exp. Biol. (N.Y.) 1956, 92, 198.

22. Grubb, R., and Laurell, A. B. Hereditary serological human serum groups. Acta path. microbiol. scand. 1956, 39, 390.

23. Lospalluto, J., and Ziff, M. Discussion. Proc. Amer. Rheum. Ass. Arthr. and Rheum. 1960, 3, 265.

24. Müller-Eberhàrd, H. J., and Kunkel, H. G. The carbohydrate of $\gamma$-globulin and myeloma proteins. J. exp. Med. 1956, 104, 253.

25. Kunkel, H. G. Macroglobulins and high molecular weight antibodies in The Plasma Proteins, F. W.
Putnam, Ed. New York, Academic Press, 1960. chap. 8, p. 279.

26. Edelman, G. M., Kunkel, H. G., and Franklin, E. C. Interaction of rheumatoid factor with antigen- antibody complexes and aggregated gamma globulin. J. exp. Med. 1958, 108, 105.

27. Müller-Eberhard, H. J., and Nilsson, U. Relation of a $\beta_{1}$-glycoprotein of human serum to the complement system. J. exp. Med. 1960, 111, 217.

28. Heremans, J. Les Globulines Sériques du Système Gamma. Paris, Masson, 1960, p. 200.

29. Conrad, M. E., Jr., Ramos, H. S., Howie, D. L., and Crosby, W. H., Jr. Waldenström's macroglobulinemia. Med. Ann. D. C. 1959, 28, 193. 